\title{
Online Communities, Critiques and Second Life Teaching in the Visual Arts
}

\author{
Susan Miiller (Corresponding author) \\ Fine and Performing Arts, State University of New York \\ New Paltz, NY 12561, USA \\ E-mail: miillers@zmail.newpaltz.edu
}

\author{
Annette Cohen \\ Fine Art and Digital Design, Great Bay Community College \\ Portsmouth, NH 03801, USA \\ E-mail: acohen@ccsnh.edu \\ Linda Smith \\ Teaching and Learning Center, State University of New York \\ New Paltz, NY 12561, USA \\ E-mail:smithl@zmail.newpaltz.edu
}

Received: July 19, 2013 Accepted: August 20, 2013 Published: September 17, 2013

doi:10.5296/ire.v1i1.4295

URL: http://dx.doi.org/10.5296/ire.v1i1.4295

\begin{abstract}
This paper demonstrates successful online studio courses where digital photographs of actual student drawings replaced seated critiques. Online studio courses excelled with integrated collaborative and social approaches to learning through the use of Web 2.0 tools. The Wimba classroom in Blackboard was used for online office hours, and synchronous small group critiques. This video enabled tool facilitated live drawing demonstrations and audio communication, conveying a synergy between students and instructors that contributed to motivation and collaboration. Discussion board forums, "About Me" essays, Camtasia
\end{abstract}


software with inset windows and narration, and critiques held in Second Life help establish a rewarding learner community. Ability to use the digital camera and Blackboard technology for class presentations and critiques demonstrate student progress to educators considering developing online courses in the arts at their institutions.

Keywords: blackboard, Camtasia, color theory, critique, discussion board, impatica, negative/positive, PowerPoint, second life, synergy, Wimba

\section{Introduction}

Online versions of existing face-to-face studio courses work well as most of the objectives are suited to an online format. The online curriculum of studio courses are very similar to the face- to-face course except for the substitution of online digitized images of student drawings rather than the physical presentation of in progress and completed student artworks. The online development of Introduction to Drawing and Design is discussed in detail in Online Development of 09105: Introduction to Drawing and Design (Miiller \& Smith, 2007). Author Miiller has taught online and face-to-face studio courses at SUNY since 1999 while Author Cohen, Distance Learning Coordinator at Great Bay Community College, has taught online and face-to-face drawing on campus for six years. Institutional concerns include replicating course objectives of demonstration, individualized attention to student progress in a studio setting, reflection and critique. Recent accreditation criteria highlight the need to confirm that work is authentically created by the student enrolled in the class. To this end, SUNY New Paltz has mandated a Student Verification of Identity be added to all online course syllabi.

The quality of online learning was investigated in Shea and Bidjerano, 2009. The researchers reviewed online learning outcomes as compared to the face-to-face class. They found that online learning was more successful and that students demonstrated higher levels of outcomes than students enrolled in the same face-to-face class. Online courses are integrating collaborative and social approaches to learning through the use of Web 2.0 tools (Alexander, 2006). Affordances to learning online include the flow and immersion of Second Life versus the "cold text" of discussion boards, student blogs, Camtasia, YouTube and video clips demonstrating drawing techniques. Synergy factors in student experiences play a role in online success such as Second Life, banners, videos, blogs. Virtual office hours using Wimba-enabled Voice Direct, allows students to ask their questions live.

Engaging learning can be afforded through the use of Web 2.0 tools that take interactivity and social presence to another level (Beldarrain, 2006). Han and Park, 2008, researched the online instructor's social presence and relationship to their students. Key theorists on distance learning pedagogies, believe that knowledge should be conveyed in learning communities (Ashcraft, Treadwell, \& Kumar, 2009; Zheng, Flygare, \& Dahl, 2009). The most popular studies represented in the media compare the outcomes of online courses and programs to their face-to-face counterparts (Bernard, Abrami, Borokhovski, Wade, Tamim, Surkes, \& Bethel, 2009; Miiller \& Smith, 2009). The authors found that face-to-face stress among peers can be a huge barrier to student learning and retention, generally among those students facing youth-based challenges of insecurity and self-consciousness. In many instances, the online course excelled. This was especially true in discussion board "critiques", where students 
experienced freedom from face-to-face stress and were far more enthusiastic and forthcoming with their comments and constructive criticism. Assignment of students to blogs and discussion board forums eased the burden of commenting so that everyone participated equally. The successful online version of a seated studio course using digital photographs of actual student drawings is demonstrated in Distance learning in the visual arts (Miiller \& Smith, 2009). In this article, Authors Miiller, Cohen and Smith wanted to research whether there were substantial individual differences both between students and between classes with respect to online learning.

\section{Teaching Tools}

Student learning and retention online improves when there is a "community" of learners (Yang, Yeh, \& Wong, 2010). Using a variety of tools such as blogs, Second Life, discussion board "critiques", virtual chats, virtual office hours, and virtual groups, this can be accomplished (Figures 5, 6, 7 and 8). Further, online instructors need to find creative ways to combat the "cold" nature of text with a variety of tools. Author Smith, Director of the Teaching and Learning Center at SUNY New Paltz, supports online teachers with a variety of web 2.0 or "cool tools" to choose from to enhance their online teaching curriculum. Virtual office hours using Wimba-enabled Voice Direct for example, allows students to ask their questions live. Camtasia and narrated powerpoints add a human element to presentations. Virtual museum visits and varied assignments such as group exercises contribute to learning and retention (Figure 8). Small group discussion protocols and their application to the online discussion forum is discussed in Getting students to talk (and think) (Burdick, 2011). Using a jigsaw protocol, small student groups studied different aspects of the course text. They used the discussion board to inform the class about their studied aspect building a more complete understanding of the text. Research into successful online learning strategies shows the value of a task can motivate the social nature of online learning (Lin, Lin, \& Laffey, 2008). Online emails and messages were often used to clarify questions students had about instructions or due dates with daily replies by the instructor. Fast response to student emails (within $24 \mathrm{hrs}$ ), and a willingness to help with technical issues can help ease and address student fear of navigating online classes. Instructor participation in discussion board forums and voice threads are essential, while virtual "cafes" offer students a place to exclusively socialize online. Affordances to online learning include "synergy", flow and immersion of the Second Life experience, student blogs, Camtasia, YouTube, video clips and video demonstrations of drawing techniques.

\section{Assignments}

An "Assignments" module located on the left course column in Blackboard, contained a series of projects. Selected examples included Negative/Positive drawings. Students were given online handouts explaining what negative and positive spaces were and how to draw them (Fig. 1). Students used a variety of media and subjects. Readings from Betty Edwards' "Drawing on the Right Side of the Brain", examples from Jacklyn St. Aubyn's "Drawing Basics" and Brooke's "Drawing as Expression" preceded the drawings. 

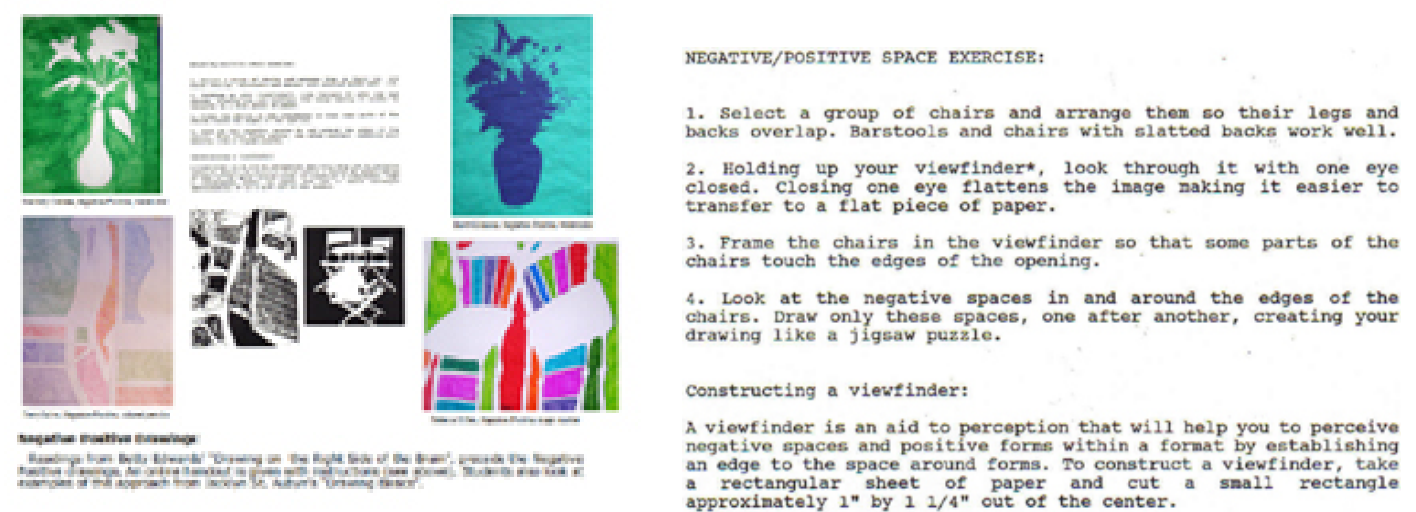

Figure 1. Negative space drawings and handout of instructions

The Value assignment included pencil shading exercises and a value drawing. Online handouts of pencil exercises, examples of value scales, and a study of the six categories of light preceded the drawings. Examples from Chaet's "The Art of Drawing" were shown to students to help them visualize these approaches. Students recreated a variety of value approaches using graphite pencils, then were instructed to create a drawing using all the values they could see. Students in the online course were very resourceful at finding useful subjects for a good value drawing (Figure 2).

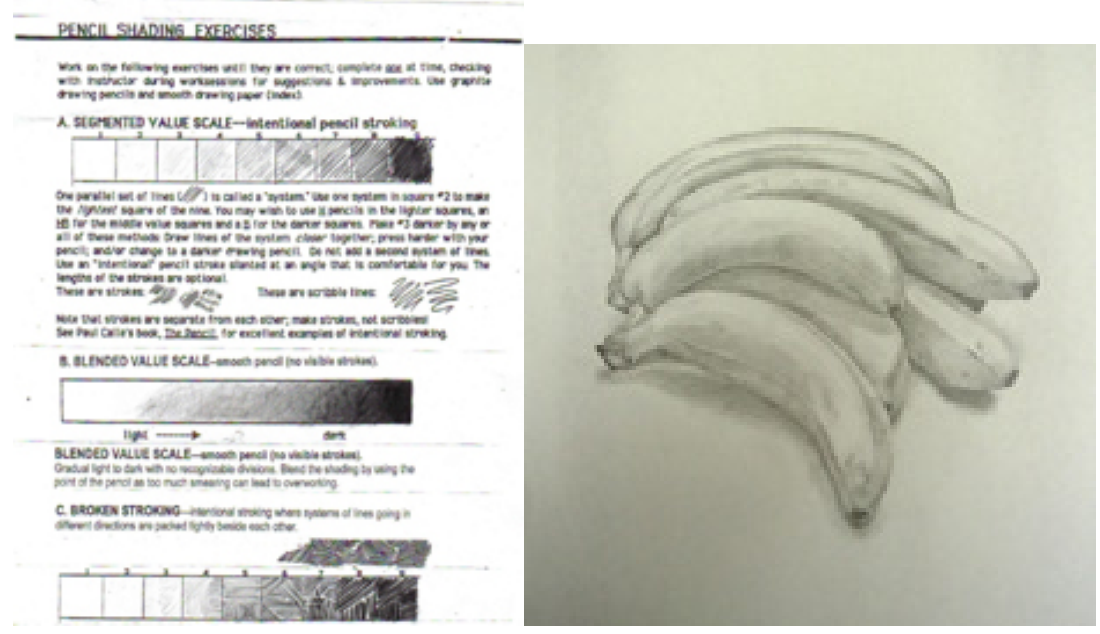

Figure 2. Pencil Shading Exercises handout printed and completed by an online student (left) and value drawing example using graphite pencil (right)

The color assignment included handouts on color theory. Figure 3 shows an important handout and resulting drawing. Students are shown examples of color pastel drawings from Teel Sale and Claudia Betti's Drawing: A Contemporary Approach. 

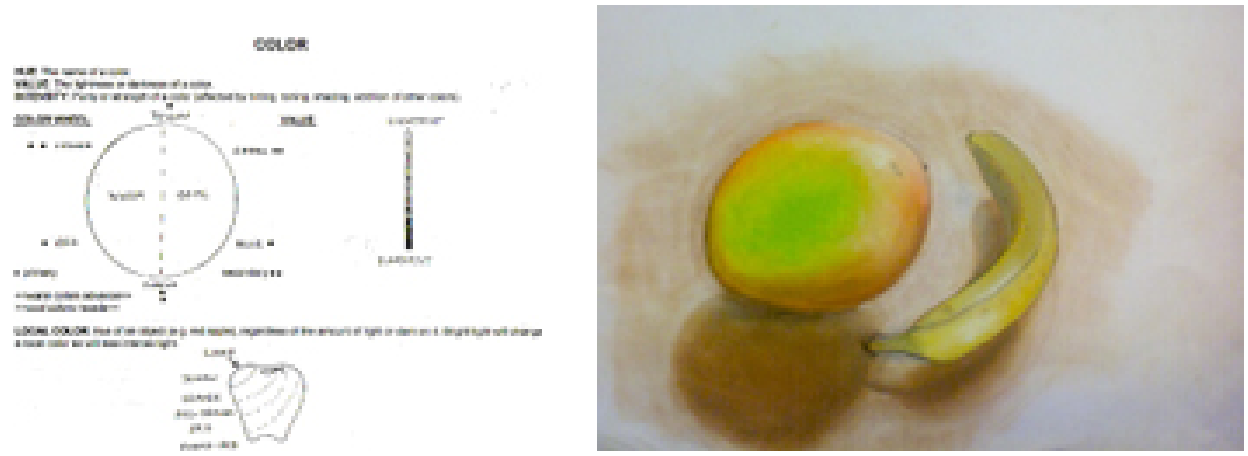

Figure 3. Color handout (left) and color drawing example using pastels (right)

Author Cohen videotaped drawing demonstrations on campus to a seated class creating an authentic scenario. Audio files outlining the assignment and reviewing chapter objectives were uploaded for each week with appropriate YouTube videos added. Live, synchronous sessions were offered in the Wimba classroom using a webcam each week, for any students needing extra pointers, demonstrations by request, or just clarification on an assignment. The Journal feature was utilized in Blackboard, enabling students to upload photographs of their assigned drawings each week, along with a written reflection. It was required that students take one photograph of their drawing in progress and another when was completed, insuring the drawing was the work of the student enrolled. Critiques took place on the Blog feature in Blackboard. At the end of the semester, students were required to physically deliver both portfolios to campus to demonstrate that the drawings were their original work.

\section{Online Critiques}

Online courses are integrating collaborative and social approaches to learning through the use of Web 2.0 tools (Alexander, 2006). Affordances to learning online include the flow and immersion of Second Life versus the "cold text" of discussion boards (Figure 4), student blogs, Camtasia, YouTube and video clips demonstrating drawing techniques. Synergy factors in student experiences play a role in online success such as Second Life (Figure 5), banners, videos, and blogs (Figures 6 and 7). Engaging learning can be afforded through the use of Web 2.0 tools that take interactivity and social presence to another level (Beldarrain, 2006).

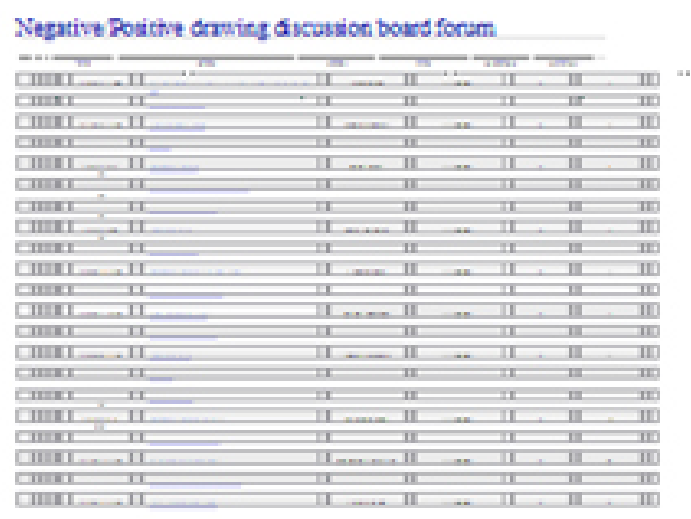

Figure 4. Discussion board forum for negative space drawing assignments 


\section{Macrothink}

Increasingly, online critiques are being held in Second Life. According to Semrau and Boyer, 2008, students have found the possibilities of the virtual world a rewarding method of learning and retaining what they have learned. Academic Computing maintains a presence in Second Life for students and faculty to explore the possibilities of the virtual world. To use Second Life, students must create an Avatar and an account with Linden Labs. Tutorials and a Second Life URL are embedded in the SUNY New Paltz, Academic Computing site at www.slurl.com/cyberPaltzPreserve.

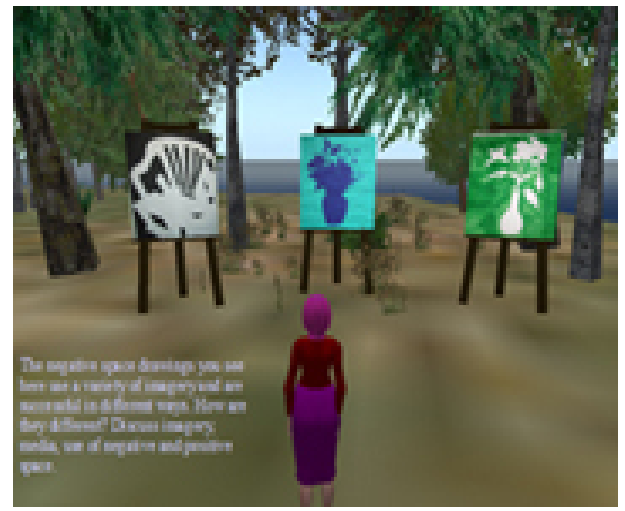

\section{Second Life Preparation}

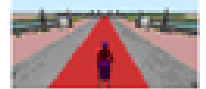

- Meet in Teaching and Leaming Center

- Set up your Avatar andits appearance.

- Leam to teleport, walk, fly, chat, commuricate and find places.

- Attend a critique in New Paltz cyber preserve's academic clearing

Figure 5. Screenshot of a Second Life critique using negative/ positive space drawings (left) and Second Life preparation (right)

To facilitate the sense of students belonging to a community of online learners, an "About Me" essay and blog assignment is the first exercise of the semester for Author Miiller's online class (Figure 6). Author Miiller's “About Me" blog is posted as well so students get a sense of their Professor as a person rather than someone just typing responses and instructional text to them (Figure 7). The authors found that students were more willing to socialize if photographs of other group members were provided. Improved commenting and friendship formation contributed to social closeness and better communication among peers. 


\section{Student "About Me" Essay}
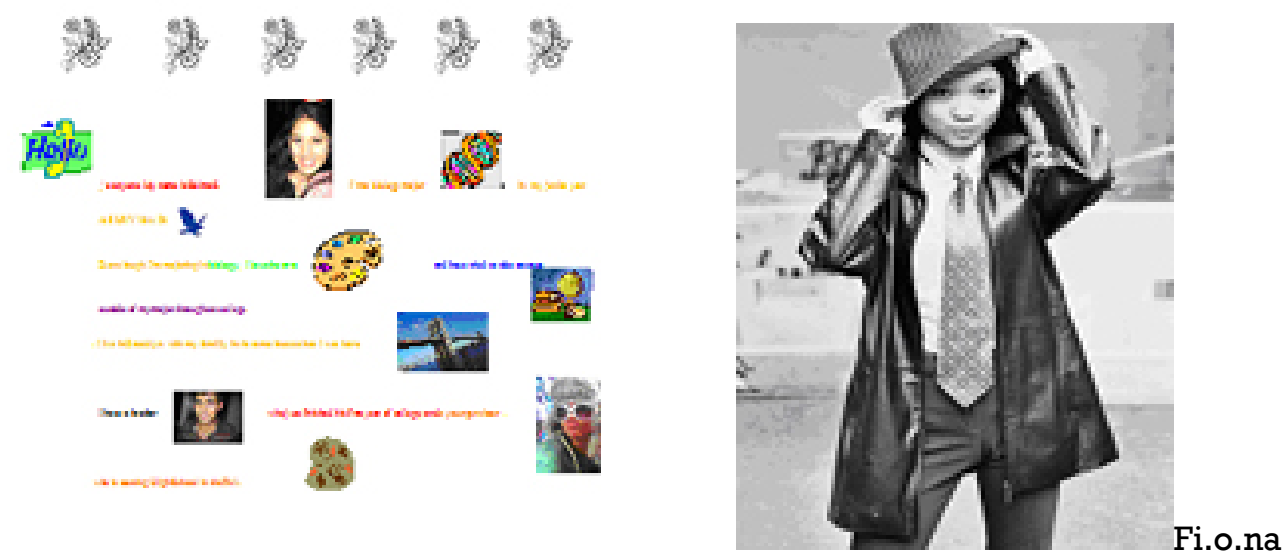

[fee-oh-nuh] - s elf-defined

My name is Fiona L. I'm 20 years old and studying for my BA in Marketing with an Asian Studies minor. I am originally from Hong Kong and moved to the United States when I was five years old. I speak Cantonese-Chinese fluently and currently learning Mandarin-Chinese.

I'm Executive Vice President of American Marketing Association and Vice President of Jam Asia at SUNY New Paltz. I'm also a campus representative for Microsoft and co-own a web design company called Cyan. Although I do not consider myself an artistic person, I like to express my creativity through photography and drawing. I currently live in Brooklyn, New York so when I have spare time, I would like to visit museums in the city to look for inspiration. I aspire to work for an advertising company in the future, and I believe creativity is the key to attract fast-pace consumers. This is my first time taking an art-related class, therefore I am hoping that I will be able to learn more about art. My goal in this class is to understand and interpret artistic values which will allow me to look beyond what is placed on a canvas, picture or drawing.

Figure 6. Student examples of "About Me" blogs
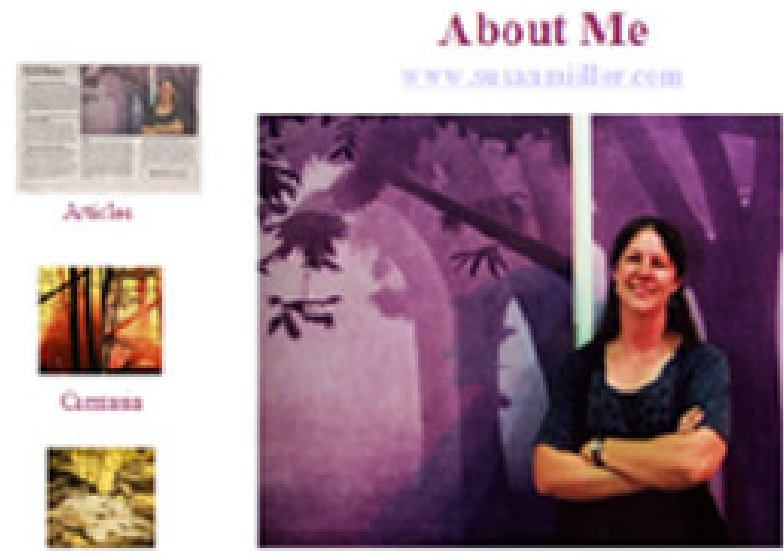

notres

Figure 7. Screen shot of Author Miiller's "About Me" blog 


\section{Macrothink}

Direct quotes from author Cohen's students share the success of the online format: "I have taken a couple of online before, and they were just totally miserable, and I thought it was because I needed the classroom setting direct dialog, the face to face experience, you know, the structure, and so it seems kind of surprising, for this class, like when I tell people, they ask, a drawing class, how is it even possible online? But it worked out actually really well, in so many aspects. Like uploading the drawings, the journals, the video demonstrations, the discussion board, because you knew how to work blackboard, because it was very organized. I can't even think of anything I didn't like about it." Another of author Cohen's students on explained that the videos were important to his learning process, not only because they demonstrated technique, that could be learned from a book, "but to see it I could see it was possible, like to draw and be relaxed, use the technique, how to hold the pencil, and stuff like that." Author Cohen's student explained that participating in the online critiques caused her less anxiety. "In class, it feels like everyone is looking at me, I don't like being the center of attention. It makes me feel nervous and embarrassed. I didn't feel that online." Author Cohen's student on the success of critique blogs: "Steve" consulted the critique blog to give him a sense of his progress in the class compared to other students. He mentioned that in an online class, it is hard to know if you are on the right track, or if you are doing the assignments right. He described "getting lost in some of the styles in the book. When I see someone do it, I can get it." When queried, he explained that he did not understand that there was room for interpretation in the assignments. "I did have difficulty with some of the work. I went in to look at everyone else's, to see how I was doing, there were some that were so good, and there were others that, I don't want to say they were bad, but made me feel better about mine. It felt good to read the comments, when people didn't leave comments, I felt that my drawing wasn't good." Figure 8 shows an actual discussion board critique with student comments from author Miiller's online Introduction to Drawing. 
NEGATIVE POSITIVE CRITIQUE BOARD: Post your drawings here by 10/14 at 11:55pm

The following students please comment on 3 drawings each: Matthew, Kaitlin, Nicholas, Kerri

\begin{abstract}
RE: Negative Positive drawing by Kaitlin
Comment by Michelle on 10/14/2011

Kaitlin your drawing was amazing. I love the idea of a mirrored image side by side almost merging together. Even with the attached pieces it's clear to see that it's two older antique style chairs. The details in the chair legs to make them appear 3 dimensional really shows in your drawing. It's very original and I think you took a different approach making it stand out even more.
\end{abstract}

Great job.

Comment by Kerri on 10/14/2011

I think you should be more proud of yourself! You did a great job! The $3 \mathrm{~d}$ effect looks amazing and I like your shading to accent the chair as it put more emphasis on the chair itself. I believe this was a difficult drawing as well but you made it through it and did well!

Comment by Kaylie on 10/17/2011

This came out great! I love black finger tips too, lol for me though, its more like black-everything always ends up on my face somehow.

RE: Negative Positive drawing by Kerri

Comment by Michelle on 10/12/2011

Hi Kerri, I too found this difficult. The concept of creating a picture without actually drawing it isn't exactly working out for me. Invisioning 3D objects on paper and making them appear that way instead of just being flat is very difficult to create on paper. This is an assignment I'd love to see an example done first hand in person. For me, I had to choose a simple object, something not 3 dimensional like a butterfly profile or full body of the butterfly or a simple flower like a daisy. I felt like it was taking the safe way out, but after attempting it, trust me, it's really not that easy! I messed up and kept drawing the object, instead of the background so it's hard to change that though process. The frame of a chair might work for you, but I think it will be hard to draw without appearing flat, hard for the non artist like us I mean! I can't wait to see the finished drawing.

Comment by Nicholas on 10/14/2011

I like the use of what appear to be director's chairs! Very nice. The overlapping of the chair legs is very nicely done. Also, what is great is that you seemed to pay attention to composition using an odd number of objects for example. Great job! Comment by Kailin on 10/17/2011

I love the director's chairs! Did you get them from pier 1 imports? haha

Figure 8. Negative positive "critique board" student comments

\title{
5. Collaboration and Culture
}

Students agreed that the online format facilitated their ability to find innovative and original solutions to creative problem solving challenges. The collaborative feature of the critique acted as their touchstone, an informal peer review process, and reassurance that they were interpreting directions and fulfilling the criteria of the assignment. One of Author Cohen's students described the critique as being an integral part of surviving the solitary lifestyle of the distance learner. However, they indicated that participation in critiques was not always an 
easy process. Students talked about not knowing what to say, or the fear of saying the wrong thing. They observed the work ethic of others with a critical eye, noting the time spent on drawing assignments. Students referred to returning to their work and making adjustments and corrections based on observations of other works and comments posted. An unspoken culture emerged; if a lengthy comment was left, it saw a positive one, and this meant your work was accepted by your peers. Highly original, divergent interpretations of assignments were especially honored and respected by students. This raises interesting questions about the nature of the disembodied online experience. In an on campus class, students drawing in close proximity often influence the work of their classmates, sometimes manifesting in convergent outcomes.

\section{Future Directions}

Questions about the nature of the disembodied online experience were raised by our research. A deeper exploration of this area of research would be well served. Students agreed that the collaborative online format facilitated their ability to find innovative and original solutions to creative problem solving challenges. Collaborative features facilitated survival of the solitary lifestyle of the distance learner. Online instructors need to research more innovative ways to combat the cold nature of text using a variety of tools such as blogs, Second Life, discussion board "critiques", virtual museum visits and small group discussion protocols. Virtual chats, virtual office hours and virtual groups using Wimba-enabled Voice Direct can add a human element to presentations and reassurance to students that they were correctly interpreting directions and fulfilling the criteria of the assignment. Support from Teaching and Learning Centers such as the one at SUNY New Paltz, can afford online teachers a variety of innovative tools to enhance their collaborative online approaches. As noted before, highly original, divergent interpretations of assignments were an unexpected benefit in online learning supporting the idea that there can be a highly qualitative aspect to the nature of the disembodied online learning experience.

\section{Conclusions}

Student learning and retention online improves when there is a "community" of learners. Using a variety of tools such as blogs, Second Life, critique boards, virtual chats, Wimba-enabled virtual office hours, and virtual groups, this can be achieved. Further, online instructors need to find creative ways to combat the "cold" nature of text with a variety of tools. Camtasia and narrated powerpoints allow students to look at and listen to their Professor. Fast response to student emails, a willingness to help with technical issues and addressing student fear contribute to a stronger online learner community. Discussion board forums with instructor participation and virtual "cafes" offer students a place to socialize. Face-to-face stress among peers can be a barrier to student learning and retention. Less face-to-face pressure affords enthusiastic commenting in discussion board forums and blogs. Professors can ease the burden of commenting by assigning students blogs and discussion board forums so everyone participates equally. Students in online versions of a studio course showed consistent development of skills, developed artistic potential, and explored processes, 
materials, and approaches to the creative experience with no loss of quality as compared to the seated version.

\section{References}

Alexander, B. (2004). Web 2.0: A new wave of innovation for teaching and learning? EDUCAUSE Review, 41(2), 32-44.

Ashcraft, D., Treadwell, T., \& Kumar, K. V. (2009). Collaborative online learning: A constructivist example. MERLOT Journal of Online Learning and Teaching, 4(1), 109-117.

Bernard, R. M., Abrami, P. C., Borokhovski, E., Wade, C. A., Tamim, R. M., Surkes, M. A., $\&$ Bethel, E. C. (2009). A meta-analysis of three types of interaction treatments in distance education. Review of Educational Research, 79(3), 1243-1289.

Brooke, S. (2002). Drawing as expression: techniques and concepts (1st ed.). Upper Saddle River, NJ: Pearson Education.

Burdick, D. (2011). Getting students to talk (and think). NEA higher education advocate, 28(6), 6-9.

Chaet, B. (1983). The art of drawing (3rd ed.). NY: Harcourt College Publishers.

Edwards, B. (1999). The new drawing on the right side of the brain. NY: Tarcher/Putnam.

Gao, F., Noh, J., \& Koehler, M. (2009). Comparing role-playing activities in second life and face-to-face environments. Journal of Interactive Learning Research, 20(4), 423-443.

Mendelowitz, D., Wakeham, D., \& Faber, D. (2003). A guide to drawing (6th ed.). Belmont: CA: Thompson/Wadsworth.

Miiller, S., \& Smith, L. (2007). Online development of 09105: Introduction to drawing and design. History community and culture: celebrating tradition and transforming our future: Selected readings of the international visual literacy association, Fort Worth, TX, 127-134.

Miiller, S., \& Smith, L. (2009). Distance learning in the visual arts. MERLOT Journal of Online Learning and Teaching, 5(3), 496-505.

Sale, T., \& Betti, C. (2008). Drawing: a contemporary approach (6th ed.). CA: Thompson/Wadsworth.

Semrau, P., \& Boyer, B. (2008). A university curriculum for a second life course. E-Learn 2008: Proceedings of the Association for the advancement of computing in education, Las Vegas, NV, 179-184.

Shea, P., \& Bidjerano, T. (2009). Measures of quality in online education: An investigation of the community of inquiry model and the net generation. Journal of Educational Computing Research, 39(4), 339-361. 


\section{Macrothink}

International Research in Education

ISSN 2327-5499

2013, Vol. 1, No. 1

St. Aubyn, J. (2007). Drawing basics (2nd ed.). CA: Thompson Learning.Wang, Q., \& Woo, H. L. (2007). Comparing asynchronous online discussions and face-to-face discussions in a classroom setting. British Journal of Educational Technology, 38(2), 272-286.

Yang, Y., Yeh, H., \& Wong, W. (2010). The influence of social interaction on meaning construction in a virtual community. British Journal of Educational Technology, 41(2), 287-306.

Zheng, R., Flygare, J., \& Dahl, L. (2009). Style matching or ability building? An empirical study on learning in well-structured and ill-structured asynchronous online learning environments. Journal of Educational Computing Research, 41(2), 195-226.

\section{Copyright Disclaimer}

Copyright reserved by the authors.

This article is an open-access article distributed under the terms and conditions of the Creative Commons Attribution license (http://creativecommons.org/licenses/by/3.0/). 